\title{
Study on Return Policy in E-Commerce Environment Based on System Dynamics
}

\author{
Liping $\mathrm{An}^{1}$, Yanmin $\mathrm{Du}^{2}$, Lingyun Tong ${ }^{2 *}$ \\ ${ }^{1}$ School of Business, Nankai University, China \\ ${ }^{2}$ School of Economics and Management, Hebei University of Technology, China \\ *tonglingyun2008@126.com
}

Keywords: electronic commerce; return policy; system dynamics

\begin{abstract}
To provide a method for manufacturers and retailers in choosing return policy in e-commerce environment, this paper builds a supply chain with one manufacturer and two retailers based on system dynamics which involves in manufacturing, purchasing, marketing and returning. By comparing the profits of the manufacturer and retailers respectively, the profitable return policy can be find out. It turns out that the manufacturer can get more profits if consumers return the goods to the retailer.
\end{abstract}

\section{Introduction}

In recent years, more and more businesses and consumers participate in electronic commerce. Because of the special nature of e-commerce, the return rate of online retail is much higher than offline retail. According to the online retailers' return rules, consumers can return goods to the retailers or to the manufacturer. The return channel will impact the manufacturers' and retailers' profits.

Previous studies on the return policy in e-commerce environment focused on two aspects, one was the return between suppliers (or manufacturers) and retailers, the other was the return between retailers (or manufacturers) and consumers.

About the return between suppliers (or manufacturers) and retailers, Reference [1] optimized the return policy of a two level supply chain, in which the manufacturer sold the returned goods at high price in the electronic market. Reference [2] studied the problem of false failure return in E-commercial activities using newsboy model, they solved the analytical solution of optimum order quantity. Reference [3] studied the effect of the return policy on the sales volume, and the results showed that looser return policy can reduce the dependence of the consumer on the product quality. Reference [4] analyzed three return channels employed by online retailers and assessed the influence of these return channels on supply chain profits, product price and product demand. Reference [5] discussed the pricing problem for a supply chain system composed of a supplier and one online retailer under E-commerce environment, considered two consumer returns processing modes: processing returns by the manufacturer or by the retailer.

About the return between retailers (or manufacturers) and consumers, reference [6] developed a profit-maximization model to obtain optimal policies for price and the return policy in terms of certain market reaction parameters. Reference [7] analyzed how to control returns costs occurred in B2C transactions in terms of returns management and returns strategy. Reference.[8] developed a profit-maximization model to obtain optimal policies for price and the return policy in terms of price and return. It obtained jointly a number of managerial guidelines for using marketing and operational strategy variables to influence the parameters so as to obtain the maximum benefit from the market. Reference.[9] tried to clarify the situation and the problems about return management of B2C web sites in China and gave out some suggestions to reduce costs and improve quality of return management, such as implementing different return policies and building up return alliance as well as adopting the TPL service. Reference [10] recognized the relationship between design quality, price of 
the product and the firm's return policy, they developed a profit-maximization model to jointly obtain optimal policies for the product quality level, price and the return policy over time.

However, there is little research using system dynamics to study on the problem of returns between the manufacturer, the retailer and the consumer. On the basis of previous studies, this paper considers a supply chain consisting of a manufacturer, two retailers and some consumers, consumers can return goods to retailers or to manufacturers. By comparing the differences of the two kinds of returns, the suitable return mode for manufacturers and retailers will be found out.

\section{Model Formulation}

2.1 Situation Description. We consider a supply chain consisting of a manufacturer, two retailers and some consumers. Retailer A and retailer B sell the same goods, order from the same manufacturer. The two retailers forecast their order quantities according to sales status, then place orders to the manufacturer. After the manufacturer receives the order, he will arrange the delivery details according to the inventory situation and forecast the next order to arrange the production.

The difference between the two retailers is that the return product generated by the retailer A's consumers is returned to retailer A himself, while the return product generated by the retailer B's consumers is returned directly to the manufacturer. The manufacturer buys back retailers' return product with a price at the end of the sales season.

The sales and return process is shown in fig.1.

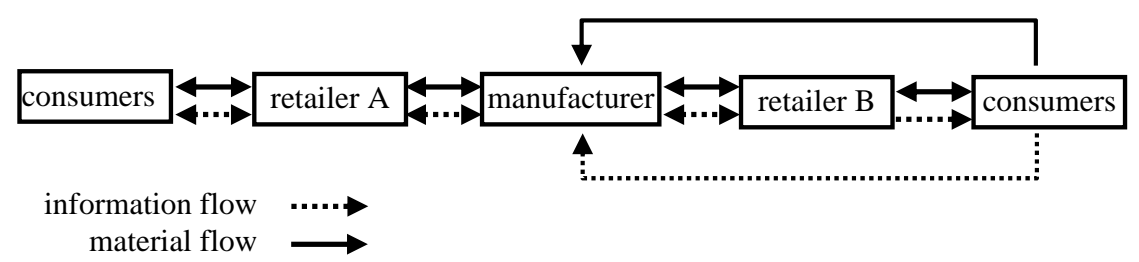

fig.1 Sales and return process

The following assumptions are made on the model:

(1)The product is offered to Retailer A and retailer B at price P1 and P2; At the end of the sales season, the manufacturer buys back retailers' return product with a price $\mathrm{R}$. The retailer B's consumer receives back P2- $\alpha$ t as the refund, where $\alpha=(\mathrm{P} 2-\mathrm{R}) / \mathrm{T} 2$ is refund coefficient, $t$ is the actual return time of retailer B's consumer, $\mathrm{T} 2$ is the maximum allowable return time of retailer $\mathrm{B}$.

(2) The returned products have no quality problems, can be sold again.

(3) The manufacturer and retailers have some initial inventory in the early days of sales period.

2.2 Flow Ggraph. The flow graph of sales and return in e-commerce environment is fig.2.

The main variables and system dynamic equations are:

(1) Manufacturer Inventory = INTE (production rate-manufacturer delivery rate1- manufacturer delivery rate $2+$ reverse distribution rate 2 , manufacturer initial inventory)

(2) Retailer A Inventory = INTE (reverse distribution rate1 + DELAY1 (manufacturer delivery rate1, receiving delay time) - sales rate1, retailer A initial inventory)

(3) Retailer B Inventory = INTE (DELAY1 (manufacturer delivery rate 2, receiving delay time) sales rate2, retailer B initial inventory)

(4) Manufacturer Profit1 = INTE (manufacturer delivery rate1*( purchase price1- unit product cost - unit inventory cost) - (manufacturer delivery rate1- sales rate1 + reverse distribution rate1)*(recover price- commodity residual value), 0 )

(5) Manufacturer Profit2 = INTE (manufacturer delivery rate2* ( purchase price2- unit product cost - unit inventory cost)- reverse distribution rate $2 *($ unit inventory cost + purchase price 2 - refund coefficient* return time2) - (manufacturer delivery rate2 - sales rate2) * recover price $+($ manufacturer delivery rate2 - sales rate 2 + reverse distribution rate2)* commodity residual value, $0)$ 
(6) Retailer A Profit= INTE (wholesale price1*( sales rate1- reverse distribution rate1)-purchase price1* manufacturer delivery rate1+ recover price*( manufacturer delivery rate1- sales rate1+ reverse distribution rate1), - inventory cost1)

(7) Retailer B Profit= INTE(sales rate2* wholesale price2 - purchase price2* manufacturer delivery rate $2+$ reverse distribution rate $2 *($ purchase price2- refund coefficient* return time2)+ recover price* (manufacturer delivery rate2- sales rate2)- manufacturer delivery rate2* wholesale price2, - inventory cost2)

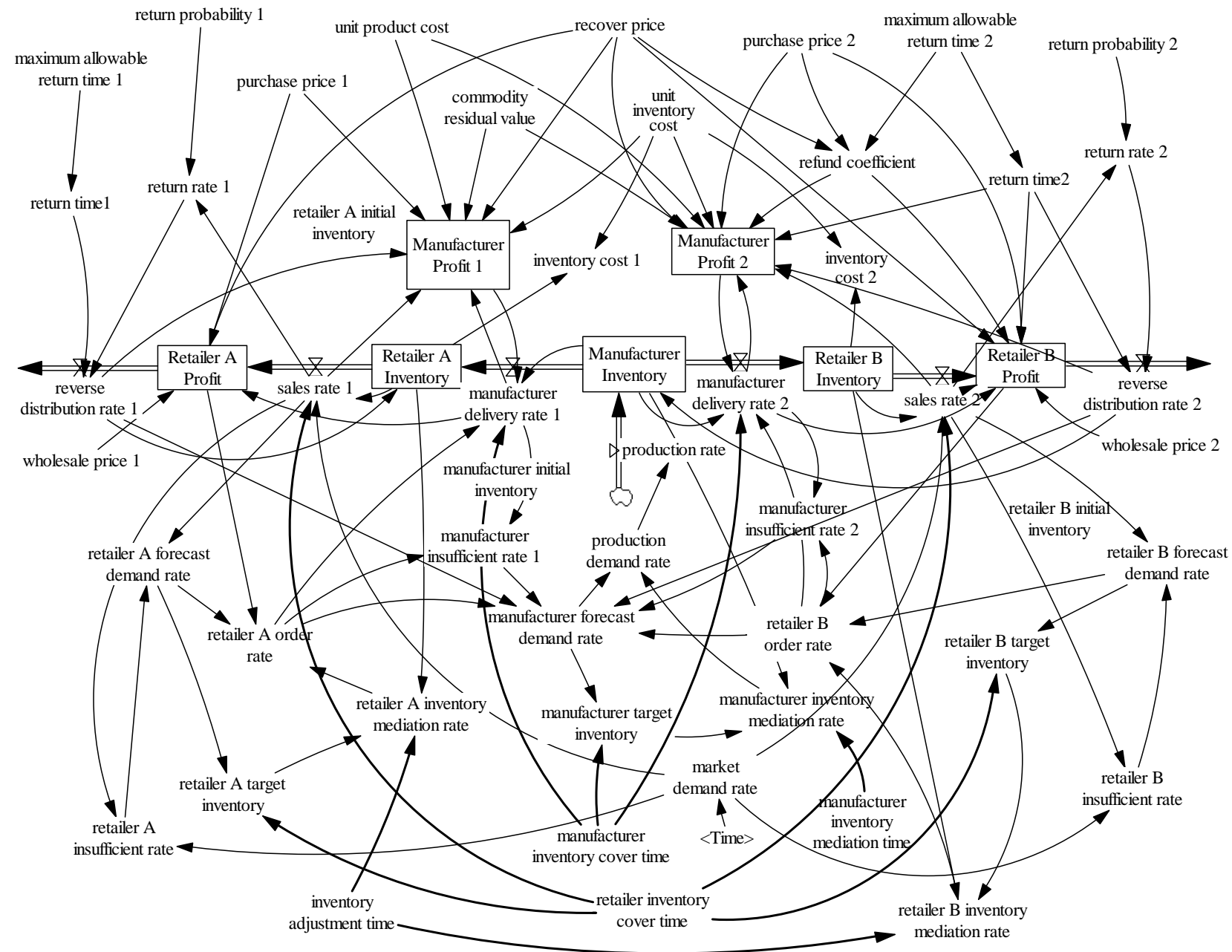

Description: variables and parameters ended in ' 1 ' are related to retailer A; variables and parameters ended in ' 2 ' are related to retailer B.

fig.2 The flow graph of sales and return in e-commerce environment

\section{Simulation And Analysis}

3.1 Model Parameters. This study sets manufacturer initial inventory, retailer A initial inventory and retailer $\mathrm{B}$ initial inventory are each 100 , the maximum allowable return time is 7 days, the consumer return rate is $30 \%$, the retailer's inventory adjustment time and the inventory cover time are each 6 days. Manufacturer and retailers unit inventory cost are each 0.25 , purchase price 1 and purchase price 2 are each 30 , wholesale price 1 and wholesale price 2 are each 50, recover price is 10 . Product demand is seasonal, and the market demand rate is shown in fig.3.

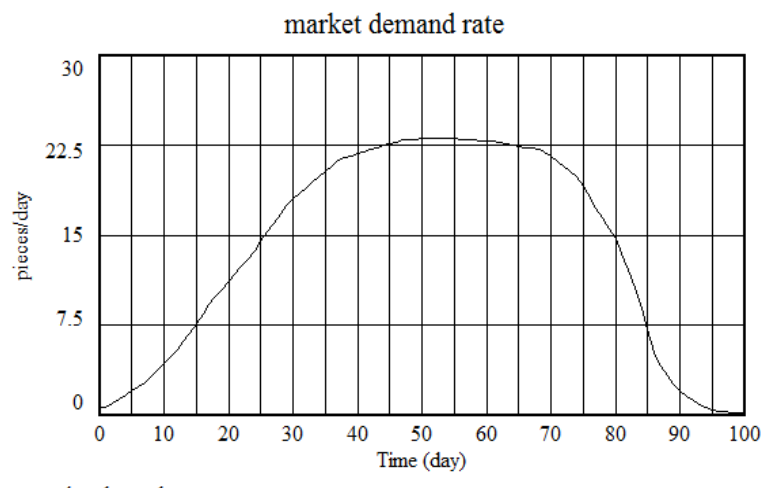

fig.3 Market demand rate 
3.2 Simulation Results and Analysis. By running the model, the profits of retailers and the manufacturer are shown in fig.4 and fig.5.
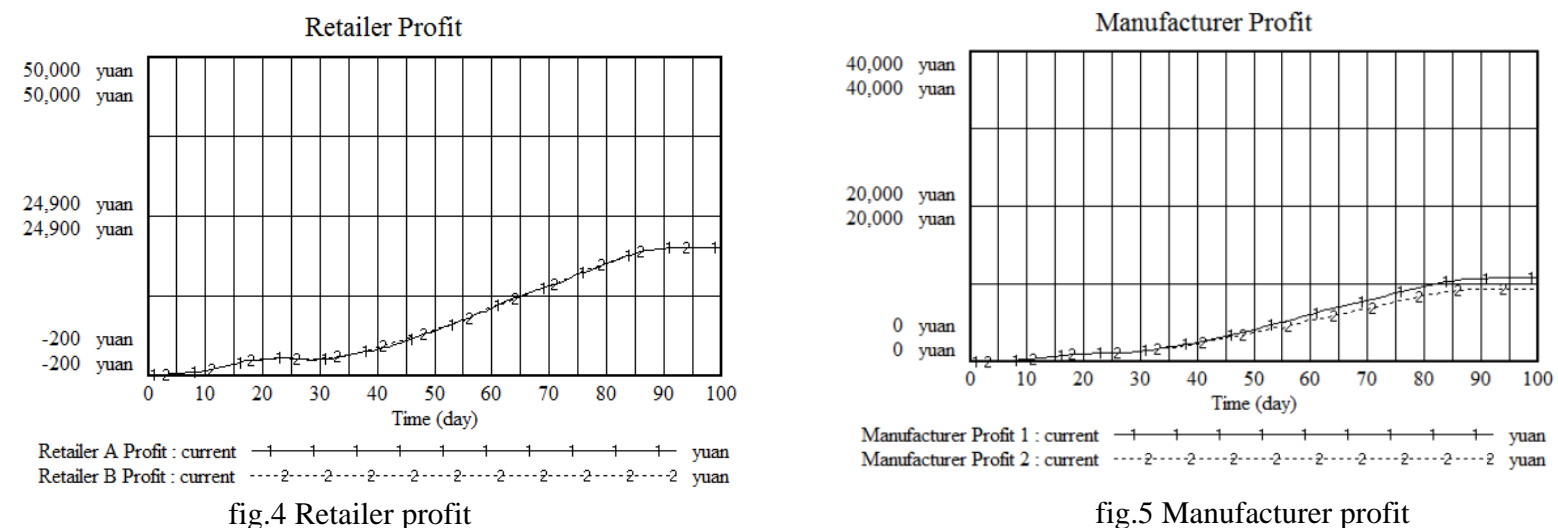

fig.5 Manufacturer profit

Fig. 4 shows that retailer A and retailer B profit is almost the same. Fig. 5 shows that manufacturer profit1 is higher than manufacturer profit2. That is, from the manufacturer's angle, retailer A can bring more profit to manufacturer. This result is easy to understand, because the manufacturer bears the inventory cost of the retailer B consumer returns. So consumers return products to retailers, this return channel has little effect on the retailer's profit, but it is more favorable to the manufacturer.

\section{Conclusions}

Today, more and more businesses and consumers participate in electronic commerce. The study models a supply chain containing a manufacturer, two retailers and some consumers by system dynamics and provides engineering presentation through simulation. The results show that consumers return to retailer or to manufacture has little influence on retailer's profit, but has more influence on manufacturer's profit. Therefore, when market demand, purchase price and wholesales price are each same, consumers return product to retailer is better than to manufacturer.

\section{References}

[1] T M. Choi, D. Li, H. Yan. 2004. Optimal returns policy for supply chain with e-market place, International Journal of Production Economics, 88(20): 201-227.

[2] J. Mostard, R. Teunter. 2006. The newsboy problem with resalable returns: a single period model and case study, European Journal of Operational Research, 169(1): 81-96.

[3] Chesnokova, Tatyana. 2007. Return policies, market outcomes, and consumer welfare, International Journal of Production Economics, 40(1): 296 - 316.

[4] C J. Zhai , Y J. Li. 2011. Study on on-line retailer's return policy in B2C mode, Journal of Industrial Engineering /Engineering Management, 25(1): 62-68.

[5] C R. Shen. 2013. Pricing decision and coordination research on consumer returns under E-commerce environment, Industrial Engineering Journal, 16(3): 21-26.

[6] L. Ding. 2005. Return policy in B2C E- business, Logistics Sci-Tech, 13(12): 81-83.

[7] G P.Jiang, X D. Li. 2005. How to control returns costs occurred in B2C, Logistics Technology, 4: 44-49.

[8] S L.Xue, Y. Xu. 2006. Integrative-optimal Investigation of Pricing and Return Policies In E-business, Operations Research and Management Science, 15(5): 132 -136.

[9] Q W. Zhao, H. Pan, Y W. Chen. 2006. Study on Return Management of B2C in China, Logistics Technology, 10: 69-72.

[10] S K. Mukhopadhyay, R. Setoputro. 2007. A dynamic model for optimal design quality and return policies, European Journal of Operational Research, 180(3): 1144-1154. 